\title{
An "All-PVC" Flexible Poly(vinyl chloride). Nonmigratory star-Poly(vinyl chloride) as Plasticizers for PVC by RAFT Polymerization
}

Zhonghe Sun, ${ }^{\mathrm{a}, \mathrm{b}, \mathrm{c}}$ Xing Mi, ${ }^{\mathrm{d}}$ Yanan Yu, ${ }^{\mathrm{e}}$ Wencheng Shi, ${ }^{\mathrm{b}}$ Anchao Feng, ${ }^{*, \mathrm{~b}}$ Graeme Moad,*,c San H. Thang*,b,c,f

a. Key Laboratory of Bio-Inspired Smart Interfacial Science and Technology of Ministry of Education School of Chemistry, Beihang University, Beijing 100191, China.

b. Beijing Advanced Innovation Center for Soft Matter Science and Engineering, College of Materials Science and Engineering, Beijing University of Chemical Technology, Beijing 100029, China.

c. Commonwealth Scientific and Industrial Research Organization (CSIRO) Manufacturing, Clayton, Victoria 3168, Australia.

d. Beijing East Simulation Software Technology Co., Beijing 100029, China.

e. Department of Math and Engineering, Puyang Vocational and Technical College, Puyang Henan 457000, China.

f. School of Chemistry, Monash University, Clayton Campus, Victoria 3800, Australia.

*To whom correspondence should be addressed.Email: fengac@mail.buct.edu.cn, graeme.moad@csiro.au;san.thang@monash.edu. 


\section{S1 RAFT polymerization of VC mediated by HECP}

Linear PVC-1, PVC-2 and PVC-3 were prepared by HECP-mediated RAFT polymerization of $\mathrm{VC}$ as previously reported. ${ }^{1}$

The preparation of linear PVC-1 is typical. HECP (0.13 g, $0.53 \mathrm{mmol}), \mathrm{ABVN}(0.02$ $\mathrm{g}, 0.08 \mathrm{mmol})$, and 1,4-dioxane $(15 \mathrm{~mL})$ were placed in the high pressure reactor. The reactor was sealed and deoxygenated through three cycles of freeze-pump-thaw cycles and backfilled with $\mathrm{N}_{2}(\mathrm{~g})$. Precondensed VC $(0.7 \mathrm{~g}, 10.6 \mathrm{mmol})$ was added to the reactor so as to give a mole ratio of $[\mathrm{M}]:[\mathrm{CTA}]:[\mathrm{I}]$ of $20: 1: 0.15$ and the reactor was sealed and heated to $45{ }^{\circ} \mathrm{C}$ for $60 \mathrm{~h}$. The excess VC was distilled from the reactor and residual reaction mixture was precipitated into methanol. The polymer, linear PVC-1, was separated by centrifugation and dried in a vacuum oven $\left(25^{\circ} \mathrm{C}, 0.7 \mathrm{kPa}\right)$ until constant weight.

Linear PVC-2 and PVC-3 were prepared by a similar procedure but using a mole ratio $[\mathrm{M}]:[\mathrm{CTA}]:[\mathrm{I}]$ of $110: 1: 0.15$ or $160: 1: 0.15$, respectively. The characterization of the linear PVC is summarized in Table 1. 
S2 NMR spectra of RAFT Agents

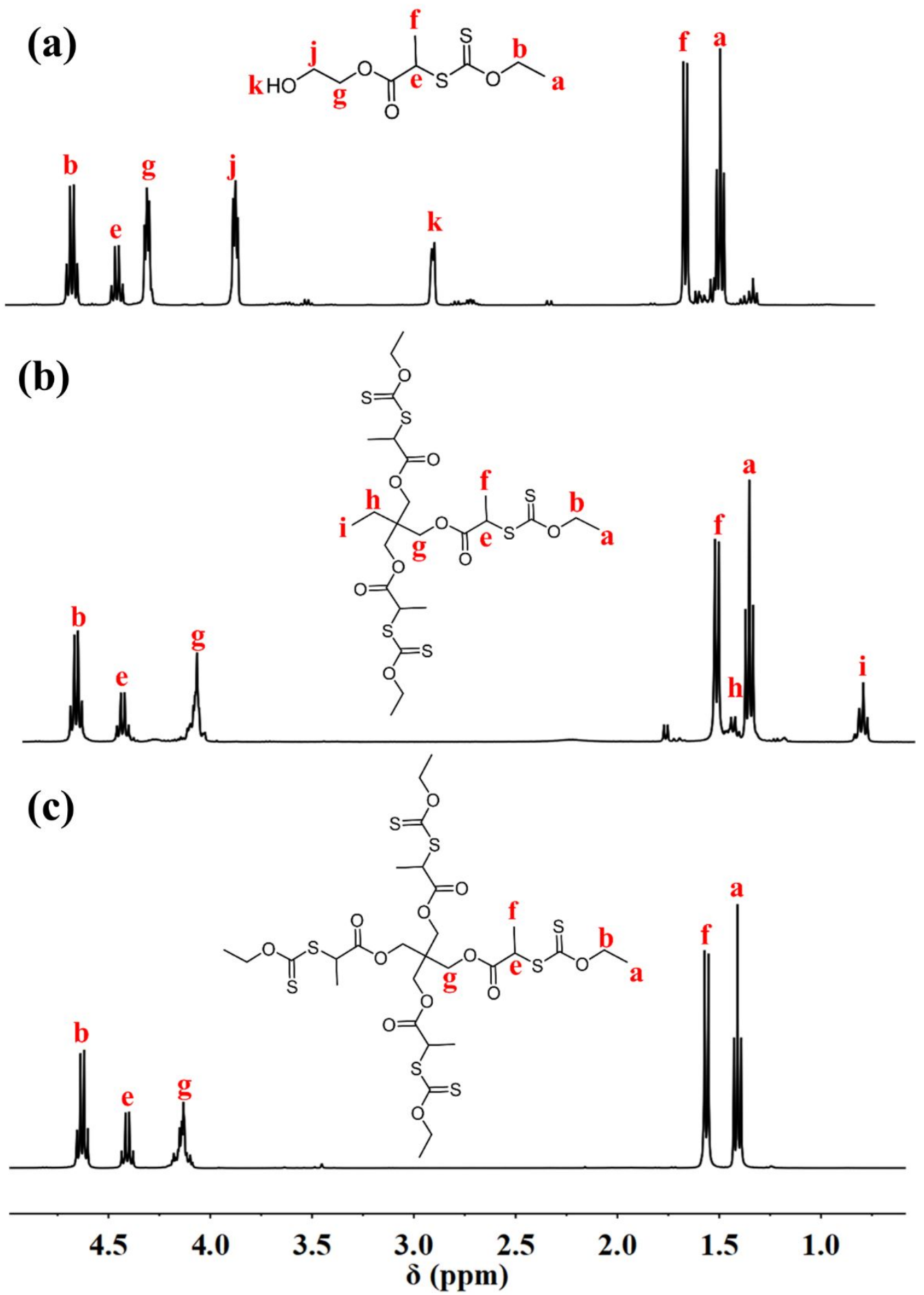

Figure S1. ${ }^{1} \mathrm{H}$ NMR spectra of (a) HECP, (b) RAFT-3 and (c) RAFT-4 in $\mathrm{CDCl}_{3}$. 


\section{S3 DOSY spectra of 3-star and 4-star-PVC}

The homogeneity of the 3-star and 4-star-PVC was examined by ${ }^{1} \mathrm{H}$ DOSY NMR. The spectra are shown in Figure S2 (3-star) and S3 (4-star). The signals associated with the RAFT agent residues and the PVC backbone have the same spin correlation time indicating that, as expected, they are part of the same macromolecule, The spin correlation times (log $D$ values) of the various samples are collected in Table S1. Although it has been reported ${ }^{2}$ that there should be a direct relationship between spin correlation time and molar mass, this is not observed for our star-PVC. While this may say something about the solution conformation of the stars, it is likely also a consequence of the spectra being obtained at similar mass concentration $(\sim 40 \mathrm{mg} / \mathrm{mL})$ rather than equal mole concentration as in the literature ${ }^{2}$ and experimental error related to the fact that molar mass range covered in the present experiments is relatively small.

Table S1. DOSY spin correlation times of 3-star-PVC-1 and DOP/4-star-PVC-1.

\begin{tabular}{lcc}
\hline Entry & Molar mass & $\log (D)^{\mathrm{a}}$ \\
\hline RAFT-3 (RAFT agent for 3-star-PVC) & 623 & 8.76 \\
3-star-PVC-1 & 1300 & 9.33 \\
3-star-PVC-2 & 2100 & 9.28 \\
3-star-PVC-3 & 5500 & 9.54 \\
RAFT-4 (RAFT agent for 4-star-PVC) & 840 & 9.00 \\
4-star-PVC-1 & 1300 & 9.22 \\
4-star-PVC-2 & 2400 & 9.27 \\
4-star-PVC-3 & 6800 & 8.98 \\
\hline
\end{tabular}

\footnotetext{
${ }^{\mathrm{a}} \log ($ spin correlation time $)$

${ }^{\mathrm{b}}$ determined for DOSY sprectrum on an impure sample (not shown).
} 
(a)

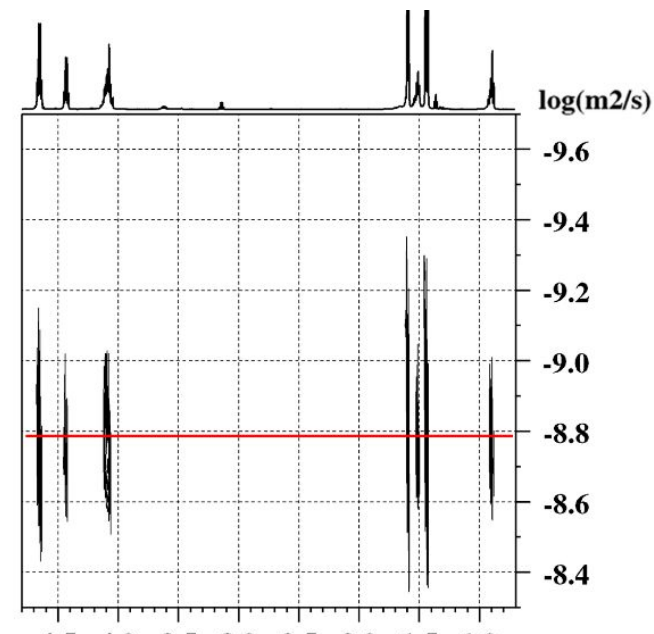

(c)
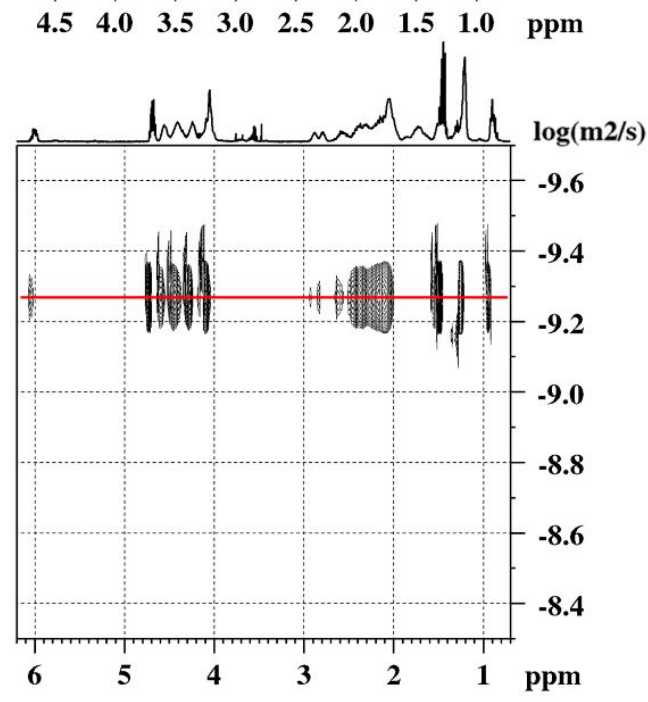

(b)

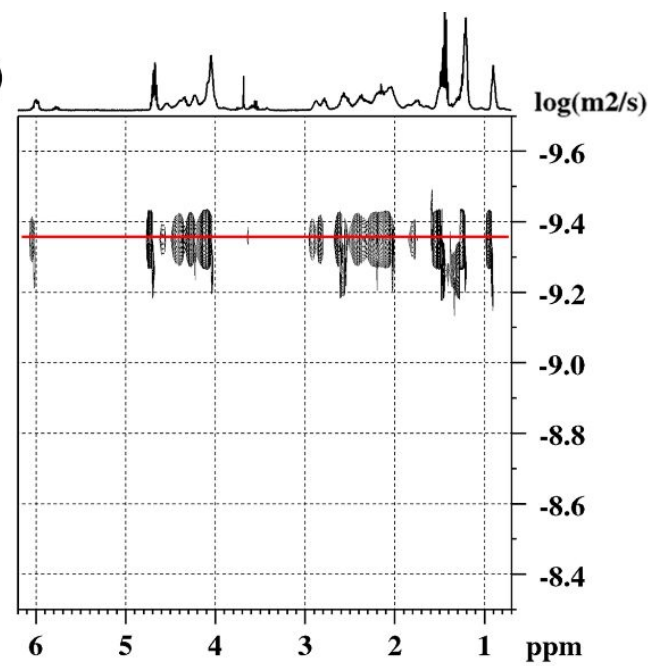

(d)

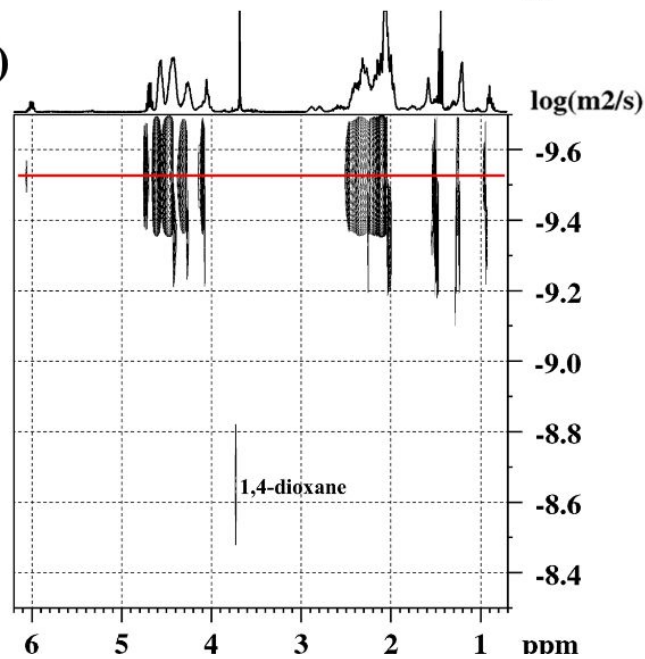

Figure S2. ${ }^{1} \mathrm{H}$ DOSY spectra $\left(\mathrm{CDCl}_{3}, 400 \mathrm{MHz}, 298 \mathrm{~K}\right)$ for (a) 3-star-PVC-1 $\left(M_{\mathrm{n}}=1300, \emptyset=1.40\right),(\mathrm{b}) 3$-star-PVC-2 $\left(M_{\mathrm{n}}=2100, \emptyset=1.57\right)$ and (c) 3-star-PVC-3 $\left(M_{\mathrm{n}}=5500, \emptyset=1.48\right)$ in $\mathrm{CDCl}_{3}$. 

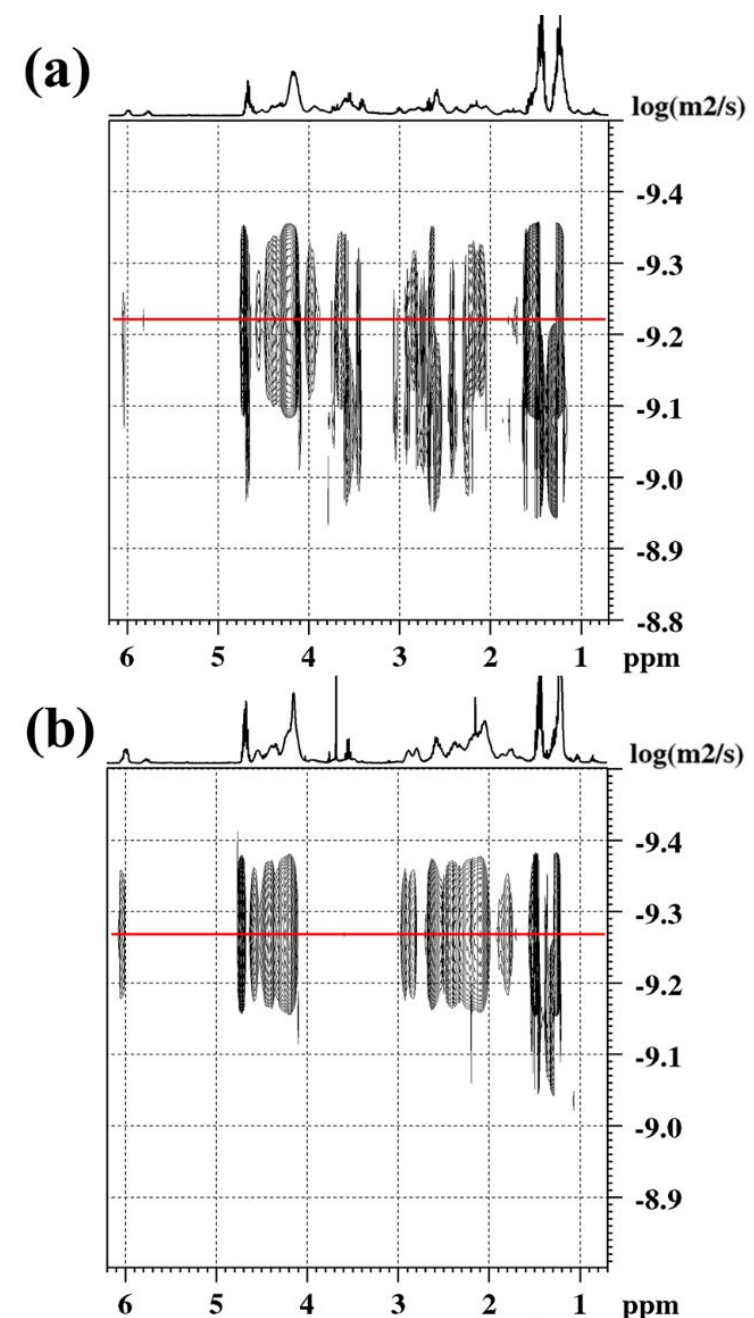

(c)
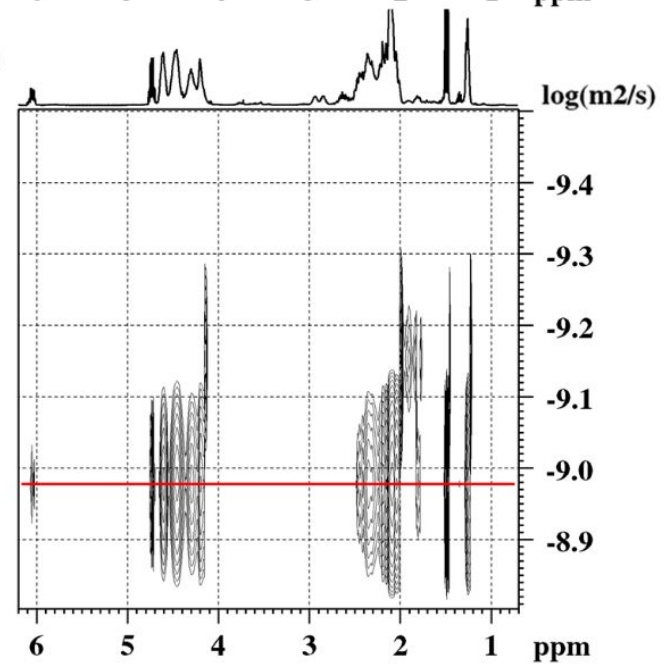

Figure S3. ${ }^{1} \mathrm{H}$ DOSY spectra $\left(\mathrm{CDCl}_{3}, 400 \mathrm{MHz}, 298 \mathrm{~K}\right)$ for (a) 4-star-PVC-1 $\left(M_{\mathrm{n}}=1300, \emptyset=1.42\right),(\mathrm{b}) 4-$ star -PVC-2 $\left(M_{\mathrm{n}}=2400, \emptyset=1.54\right)$ and (c) 4--star-PVC-3 $\left(M_{\mathrm{n}}=6800, \emptyset=1.35\right)$ in $\mathrm{CDCl}_{3}$. 


\section{S4 HMBC and HSQC NMR spectra of 3-star and 4-star-PVC}

The chemical shift assignments for 3 -star and 4-star-PVC-3 were proven by the ${ }^{1} \mathrm{H}-{ }^{13} \mathrm{C}$ HMBC and HSQC spectra.

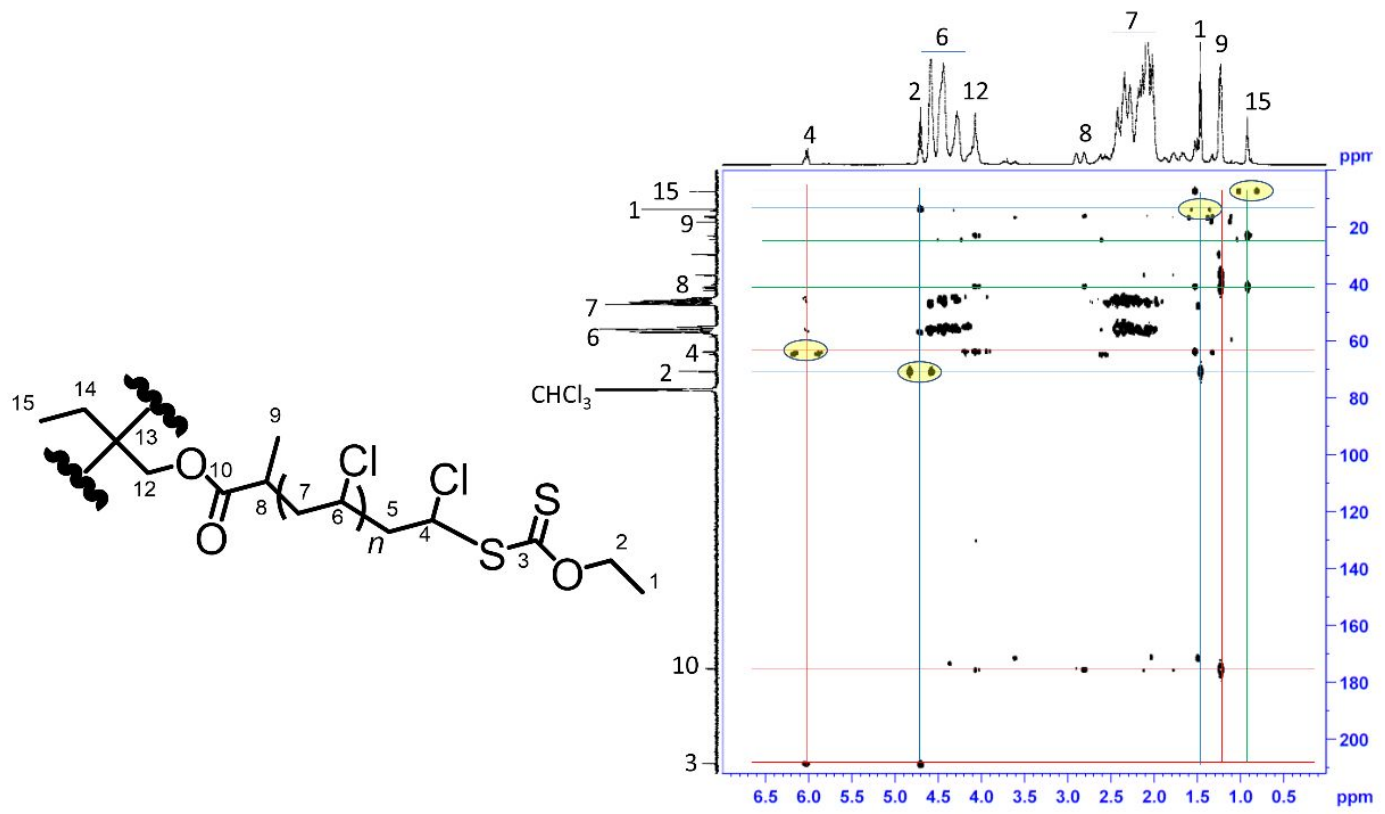

Figure S4. ${ }^{1} \mathrm{H}-{ }^{13} \mathrm{C}$ HMBC spectra $\left(\mathrm{CDCl}_{3}, 400 \mathrm{MHz}, 298 \mathrm{~K}\right)$ for 3-star-PVC-3 $\left(M_{\mathrm{n}}=5500, \emptyset=1.48\right)$ in $\mathrm{CDCl}_{3}$.

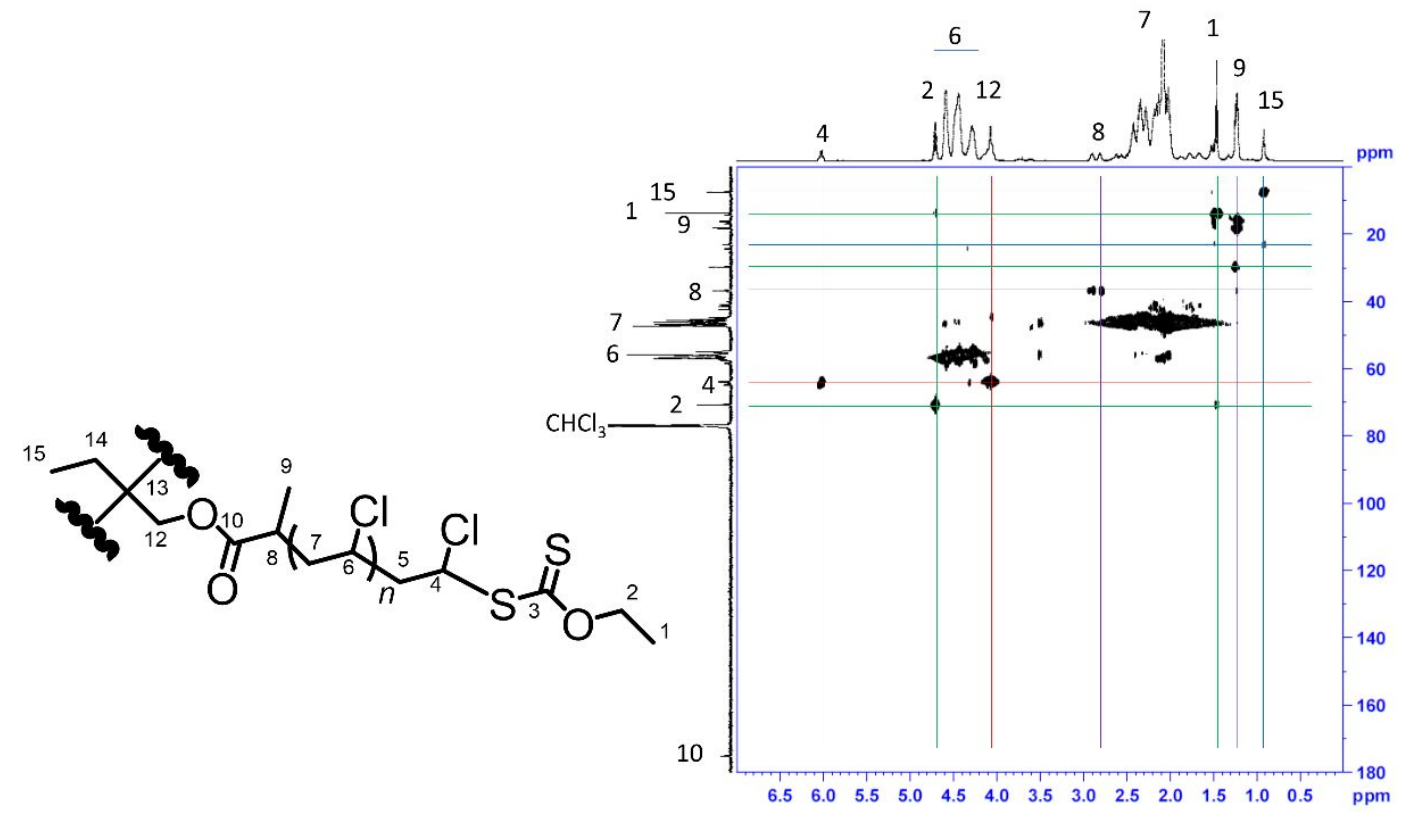

Figure S5. ${ }^{1} \mathrm{H}-{ }^{13} \mathrm{C}$ HSQC spectra $\left(\mathrm{CDCl}_{3}, 400 \mathrm{MHz}, 298 \mathrm{~K}\right)$ for 3-star-PVC-3 $\left(M_{\mathrm{n}}=5500, \emptyset=1.48\right)$ in $\mathrm{CDCl}_{3}$. 


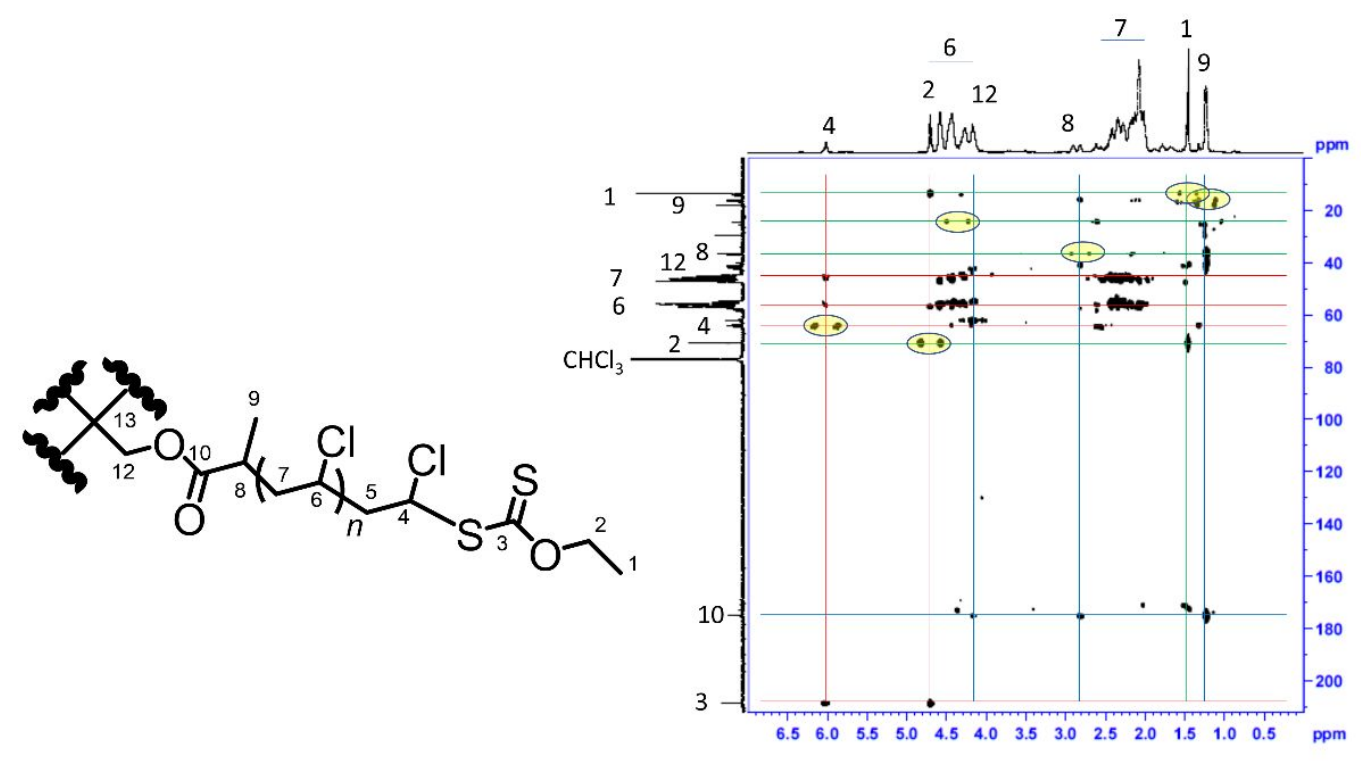

Figure S6. ${ }^{1} \mathrm{H}-{ }^{13} \mathrm{C}$ HMBC spectra $\left(\mathrm{CDCl}_{3}, 400 \mathrm{MHz}, 298 \mathrm{~K}\right)$ 4-star-PVC-3 $\left(M_{\mathrm{n}}=6800\right.$, $Ð=1.35)$ in $\mathrm{CDCl}_{3}$.

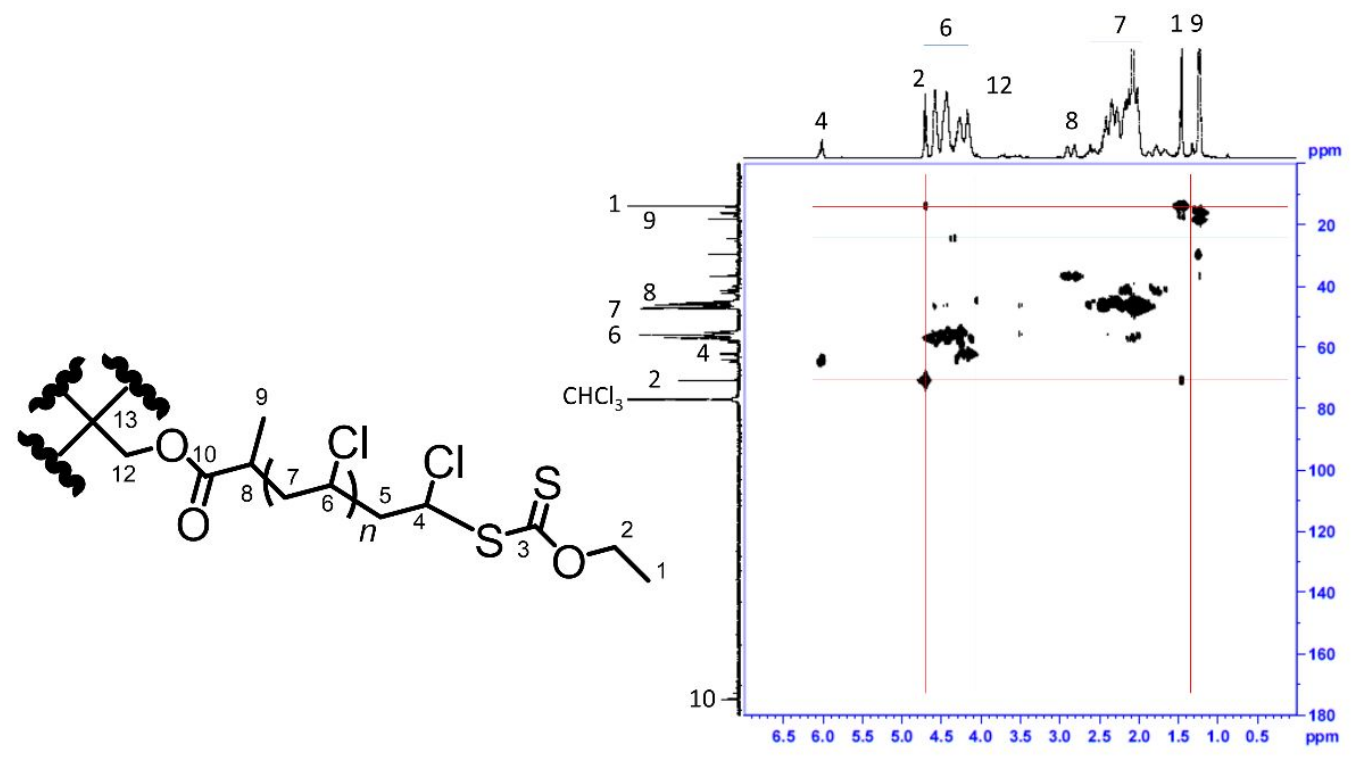

Figure S7. ${ }^{1} \mathrm{H}-{ }^{13} \mathrm{C}$ HSQC spectra $\left(\mathrm{CDCl}_{3}, 400 \mathrm{MHz}, 298 \mathrm{~K}\right)$ 4-star-PVC-3 $\left(M_{\mathrm{n}}=6800\right.$, $Ð=1.35)$ in $\mathrm{CDCl}_{3}$. 


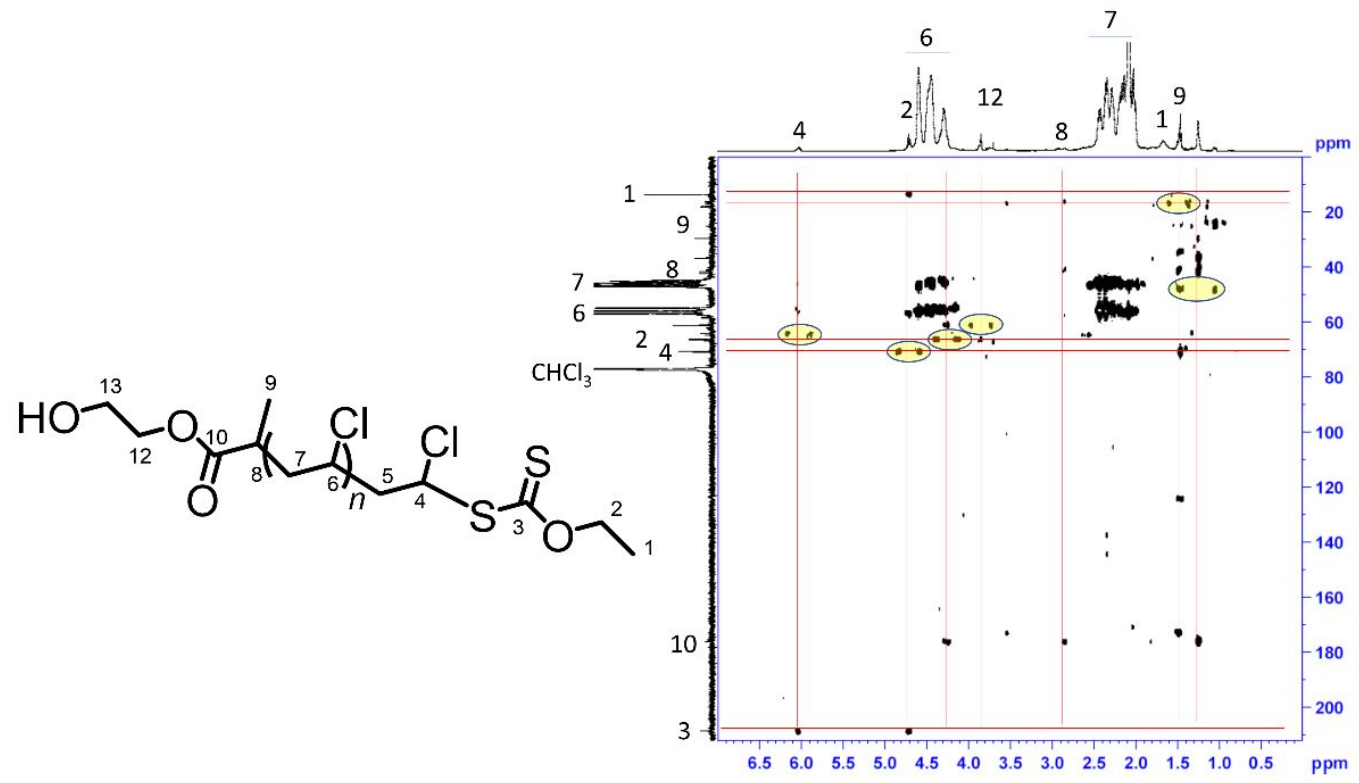

Figure S8. ${ }^{1} \mathrm{H}-{ }^{13} \mathrm{C}$ HMBC spectra $\left(\mathrm{CDCl}_{3}, 400 \mathrm{MHz}, 298 \mathrm{~K}\right) \mathrm{PVC}-\mathrm{OH}\left(M_{\mathrm{n}}=6600\right.$, $Ð=1.28)$ in $\mathrm{CDCl}_{3}$. 


\section{S5 GPC traces for 3-star and 4-star-PVC}

GPC traces of 3-star and 4-star-poly(vinyl chloride) (PVC) are shown in Figure S9. The stars all show a tail to high molar mass possibly indicative of star-star coupling. The breadth of the cross peaks in the DOSY spectra (Section 2.0) may be consistent with this. The peaks at low molar mass ( 300 PS equivalents) are an artefact. Details of the GPC characterization and the instrument used are in the Experimental.

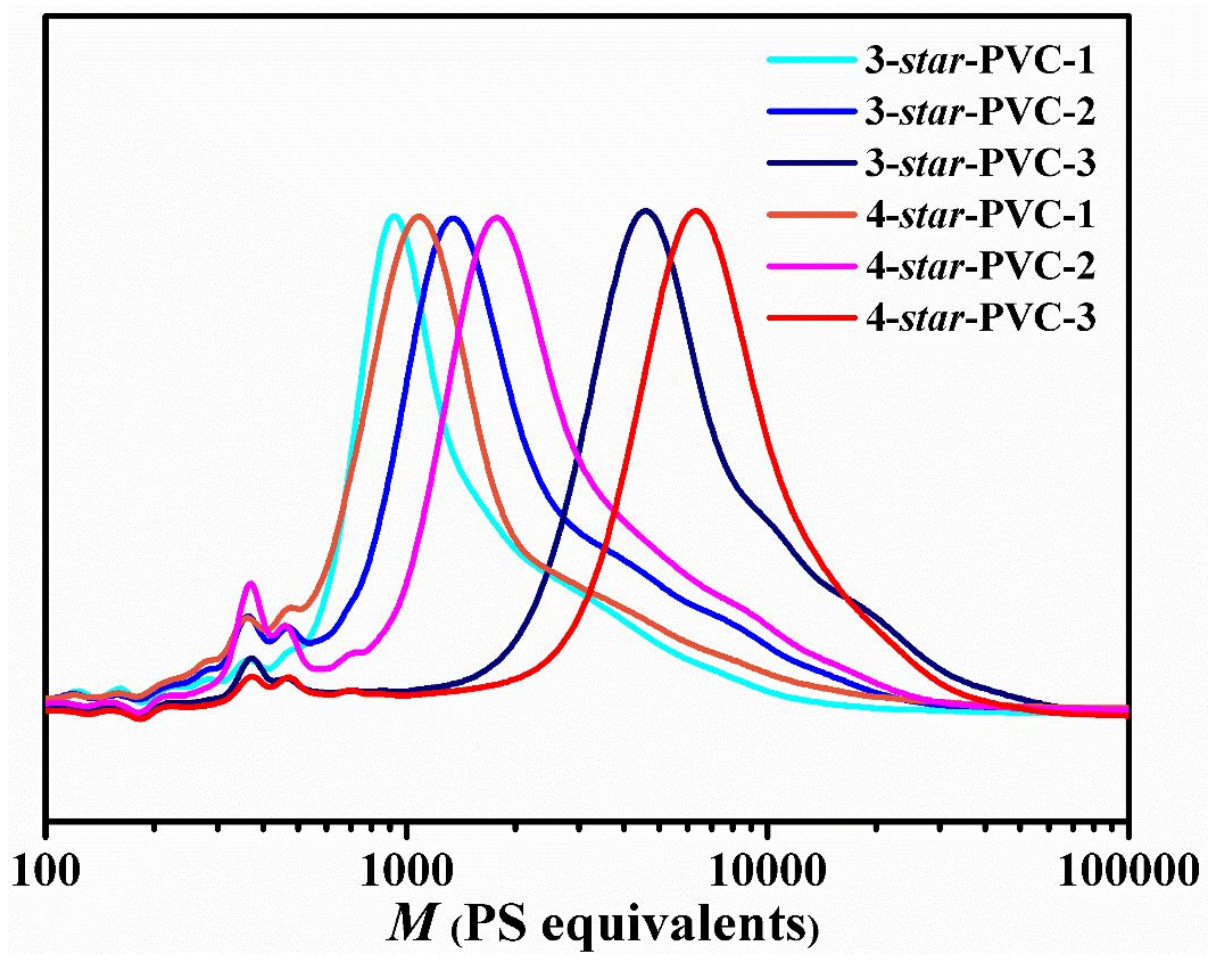

Figure S9. GPC traces of 3-star and 4-star-poly(vinyl chloride) (PVC). 


\section{S6 Migration studies}

\section{S6.1 Calibration curve for dioctyl phthalate (DOP) in $n$-hexane}

The FTIR calibration curve used to estimate the migration of dioctyl phthalate from DOP plasticized PVC is shown in Figure S9. Details of the migration tests are in the Experimental.

(a)
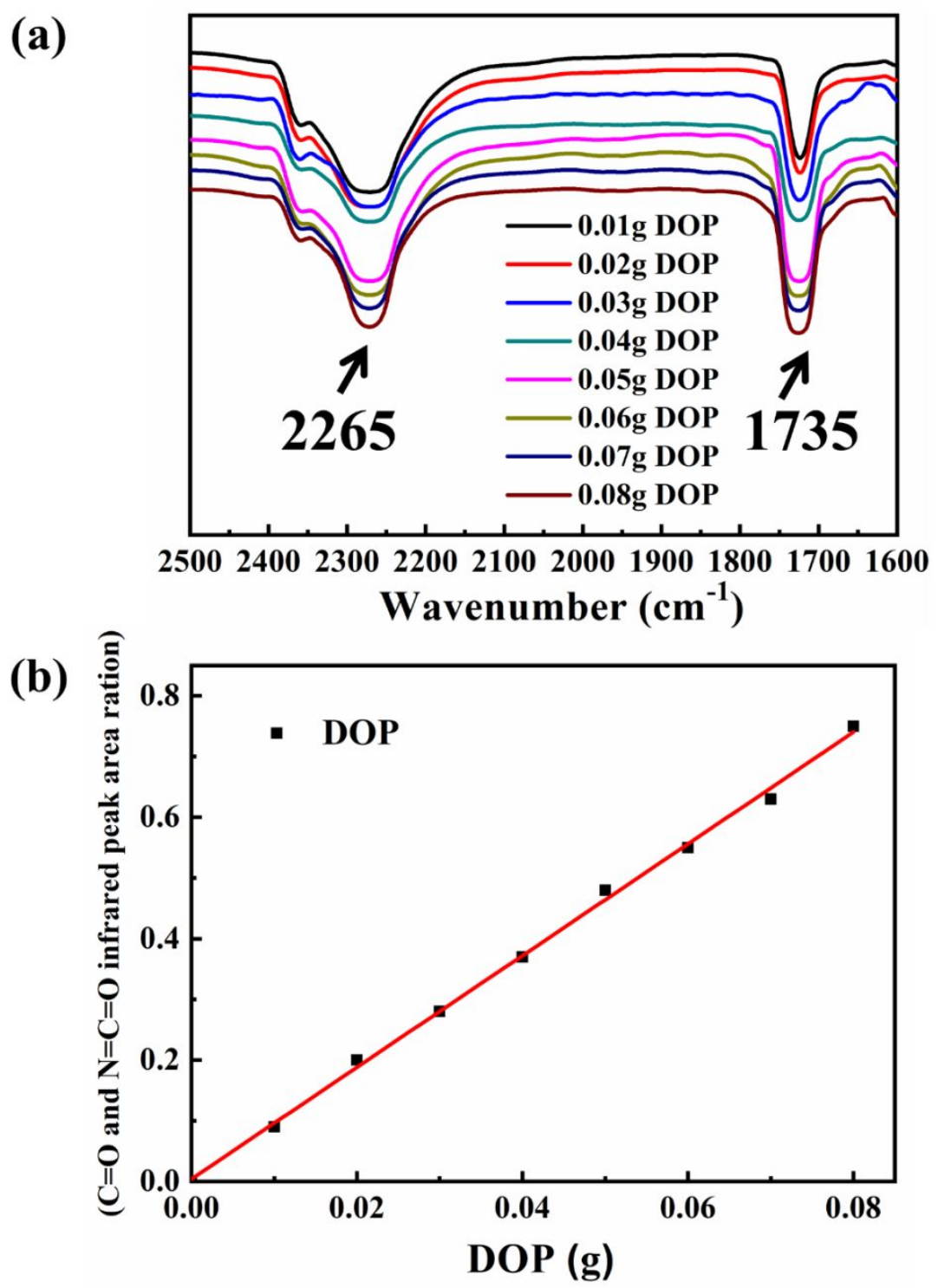

Figure S10. (a) Infrared spectra of DOP and 1,6-hexamethylene diisocyanate $(0.02 \mathrm{~g})$ in $10 \mathrm{~mL} n$-hexane solution; (b) calibration curve of the DOP in $10 \mathrm{~mL} n$-hexane solution. 
S6.2 Migration data for dioctyl phthalate (DOP) and star-PVC plasticizers in $\boldsymbol{n}$ hexane

(a)

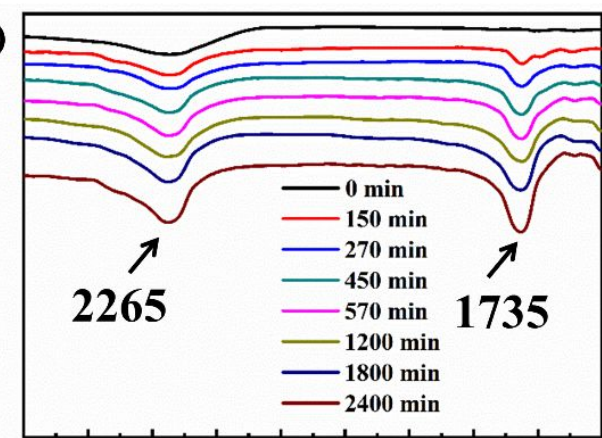

2500240023002200210020001900180017001600

Wavenumber $\left(\mathrm{cm}^{-1}\right)$

(c)

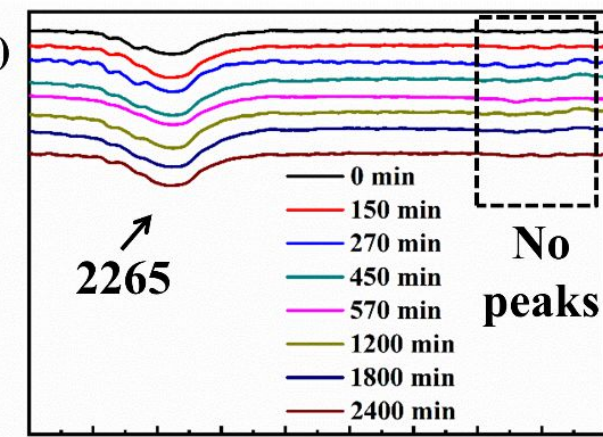

2500240023002200210020001900180017001600

Wavenumber $\left(\mathrm{cm}^{-1}\right)$ (b)

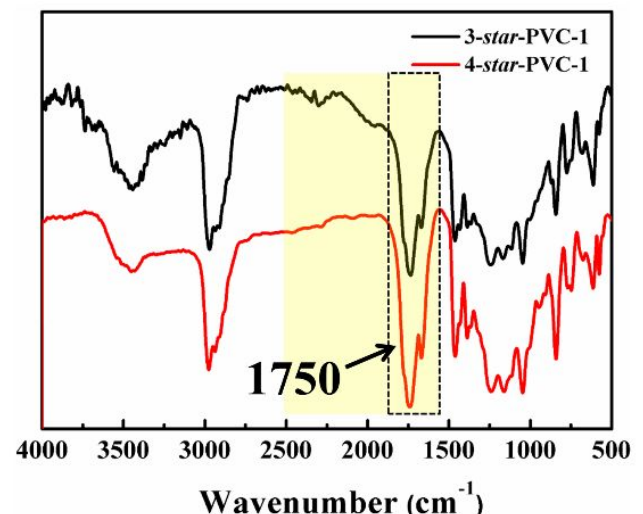

(d)

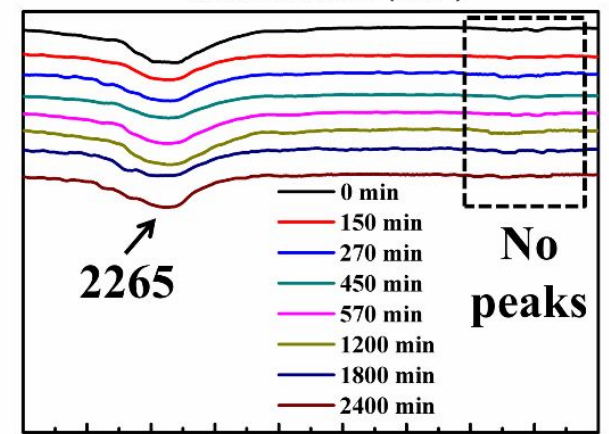

2500240023002200210020001900180017001600 Wavenumber $\left(\mathrm{cm}^{-1}\right)$

Figure S11. Infrared spectra of extraction liquid from (a) DOP (0.2g), (b) 3-starPVC-1 (0.2g) plasticized PVC (0.5g) and (c) 4-star-PVC-1 (0.2g) plasticized PVC $(0.5 \mathrm{~g})$ at different extraction time 


\section{S7 Thermogravimetric analysis}

Figures S12 and S13 allow the observed temperatures for 10\% and 50\% weight loss for the star-PVC to be compared with those for commercial PVC. These values represent a traditional method for comparing thermal stability. In the present case such data is complicated by the present of a low temperature weight loss peak (see text for discussion).

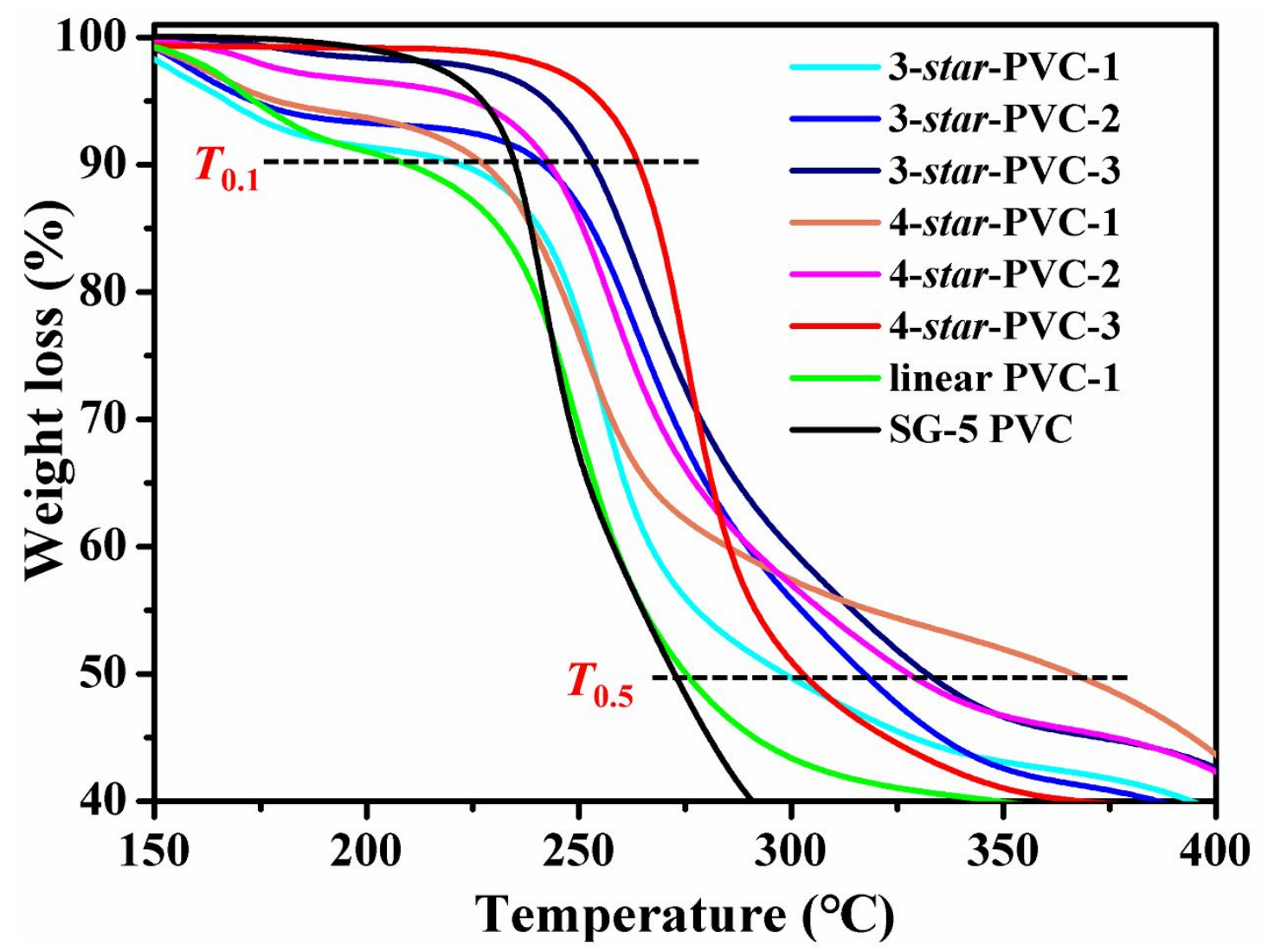

Figure S12. Part of TGA thermograms of different PVC samples. 


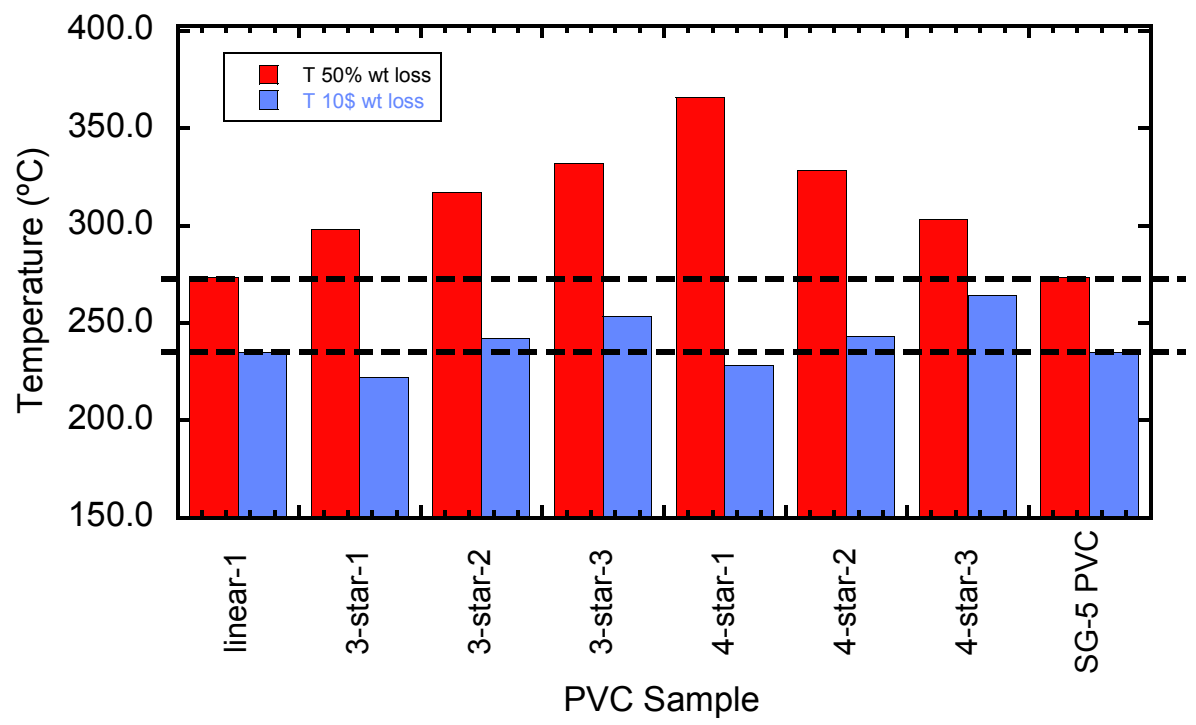

Figure S13. Comparison of temperatures for $10 \%$ and 50\% weight loss for different PVC samples. The dashed horizontal lines correspond to the values for commercial PVC (SG-5).

We believe a more meaningful way to compare thermal stability in the present instance is to compare the peak rate loss temperatures as evaluated from the peaks in the DTG curves. The comparison is shown in Figure S14. For discussion and DTG curves see text. The data indicate the stars are more resistant to dehydrochlorination than commercial PVC and linear RAFT synthesized PVC. The stability tends to increase with star molar mass.

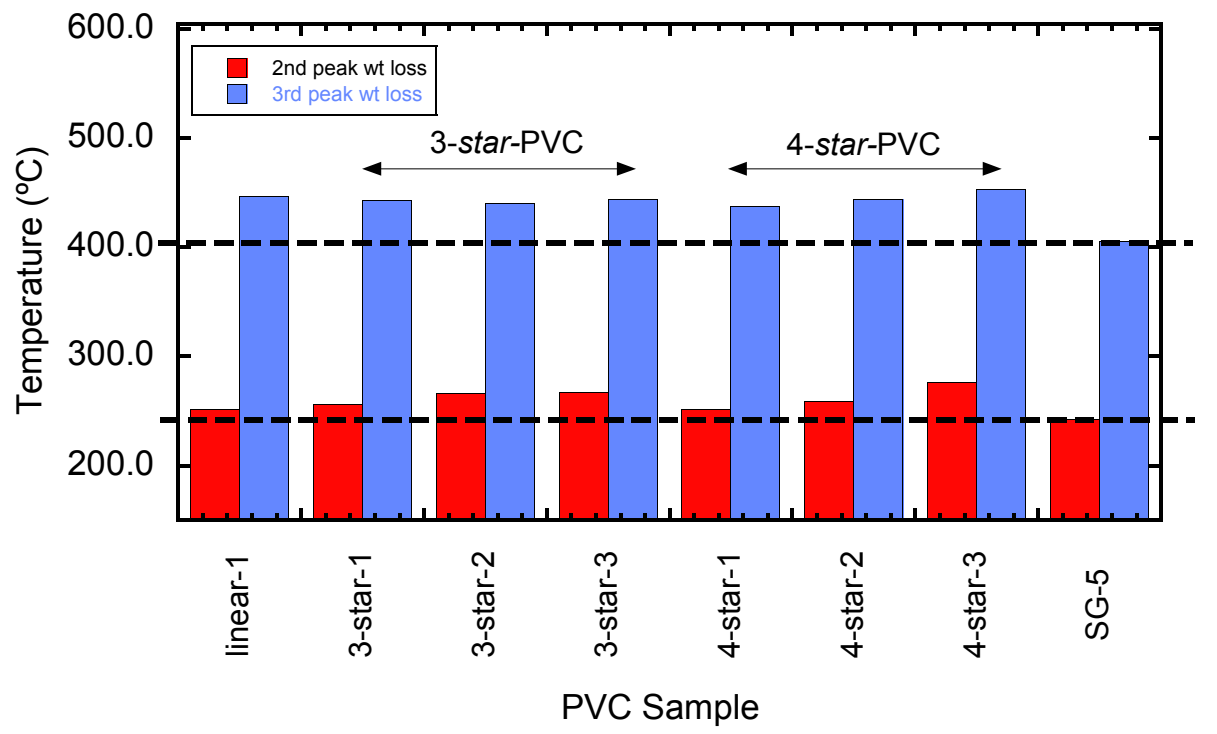

Figure S14. Comparison of the peak mass loss temperatures for different PVC samples. The dashed horizontal lines correspond to the values for commercial PVC (SG-5). 


\section{S8 Tensile properties}

Table S2. Tensile properties for PVC (SG-5) and for PVC/DOP, PVC/3-star-PVC-1, PVC/4-star-PVC-1 and PVC linear PVC-1 blends.

\begin{tabular}{lcccc}
\hline & $\begin{array}{c}\text { Tensile } \\
\text { Entry }\end{array}$ & $\begin{array}{c}\text { Elongation } \\
\text { at break }\end{array}$ & $\begin{array}{c}\text { Young's } \\
\text { modulus }\end{array}$ & $\begin{array}{c}\text { Plasticization } \\
\text { efficiency }{ }^{a}\end{array}$ \\
& $(\mathrm{MPa})$ & $(\%)$ & $(\mathrm{MPa})$ & $(\%)$ \\
\hline Neat PVC (SG-5) & 22.2 & 167.7 & 238.4 & 0 \\
PVC/DOP (10 wt\%) & 15.5 & 278.3 & 16.5 & 67.7 \\
PVC/DOP (20 wt\%) & 17.1 & 304.8 & 17.2 & 83.9 \\
PVC/DOP (30 wt\%) & 16.9 & 331.1 & 24.9 & 100.0 \\
PVC/3-star-PVC-1 (10 wt\%) & 11.0 & 343.4 & 9.7 & 107.5 \\
PVC/3-star-PVC-1 (20 wt\%) & 10.5 & 352.3 & 8.1 & 113.0 \\
PVC/3-star-PVC-1 (30 wt\%) & 11.0 & 364.2 & 8.4 & 120.3 \\
PVC/4-star-PVC-1 (10 wt\%) & 10.7 & 342.0 & 7.9 & 106.7 \\
PVC/4-star-PVC-1 (20 wt\%) & 11.2 & 358.4 & 9.5 & 113.7 \\
PVC/4-star-PVC-1 (30 wt\%) & 11.1 & 379.1 & 10.4 & 129.3 \\
PVC/linear PVC-1 (30 wt\%) & 14.9 & 171.6 & 177.4 & 2.4 \\
\hline
\end{tabular}

${ }^{a}$ The plasticization efficiency of plasticized PVC was calculated using the formula plasticization efficiency $=[($ ultimate elongation of plasticized PVC)-(ultimate elongation of neat PVC)]/ [(PVC/DOP (30 wt\%))-(ultimate elongation of neat PVC)] 


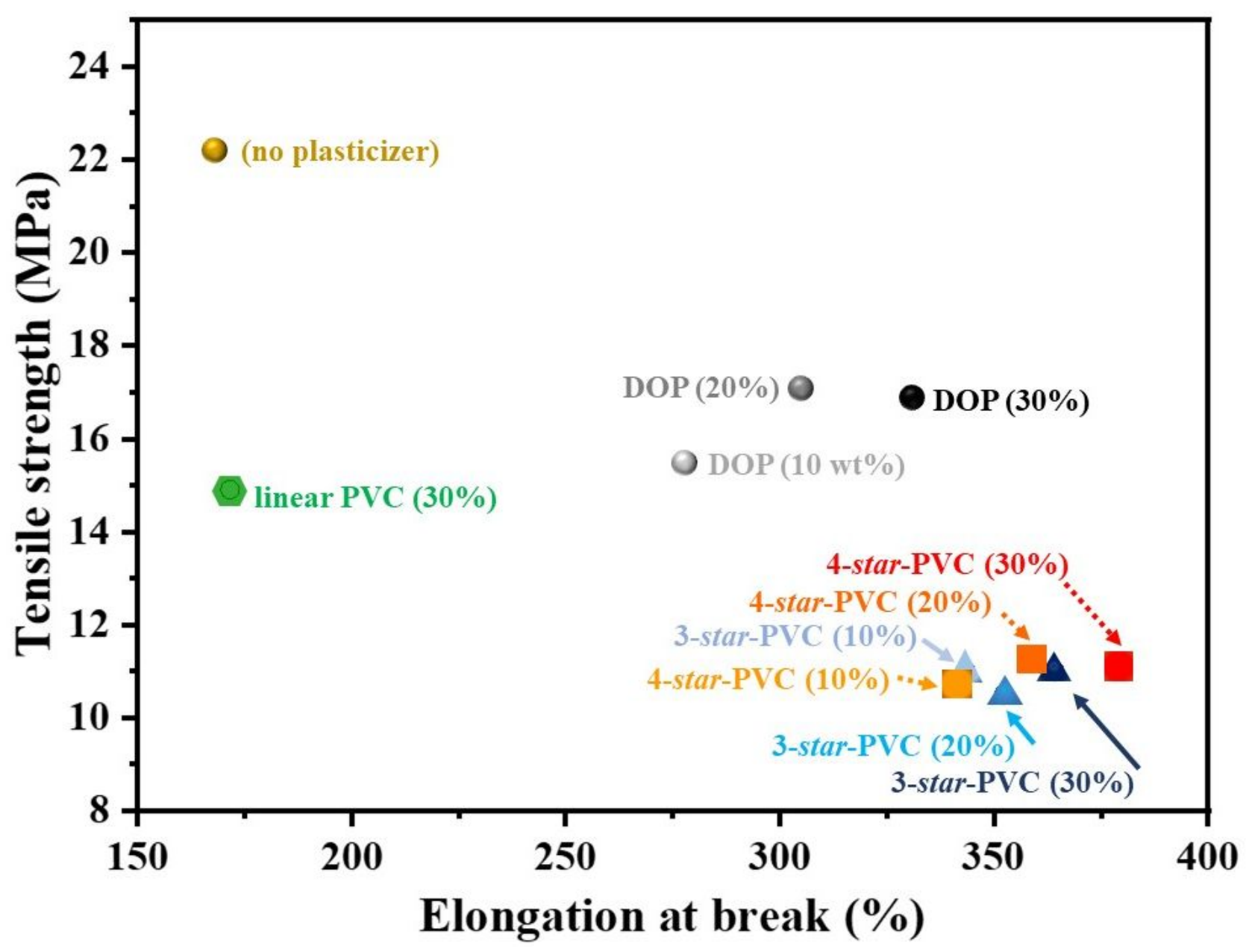

Figure S15. Elongation at break and tensile strength results for PVC (SG-5) and the same PVC plasticized with various amounts of low molar mass linear PVC-1, 3-star-PVC-1, 4-star PVC-1 and with dioctyl phthalate (DOP). Data summarized in Table S2.

S9 Molar mass of PVC 


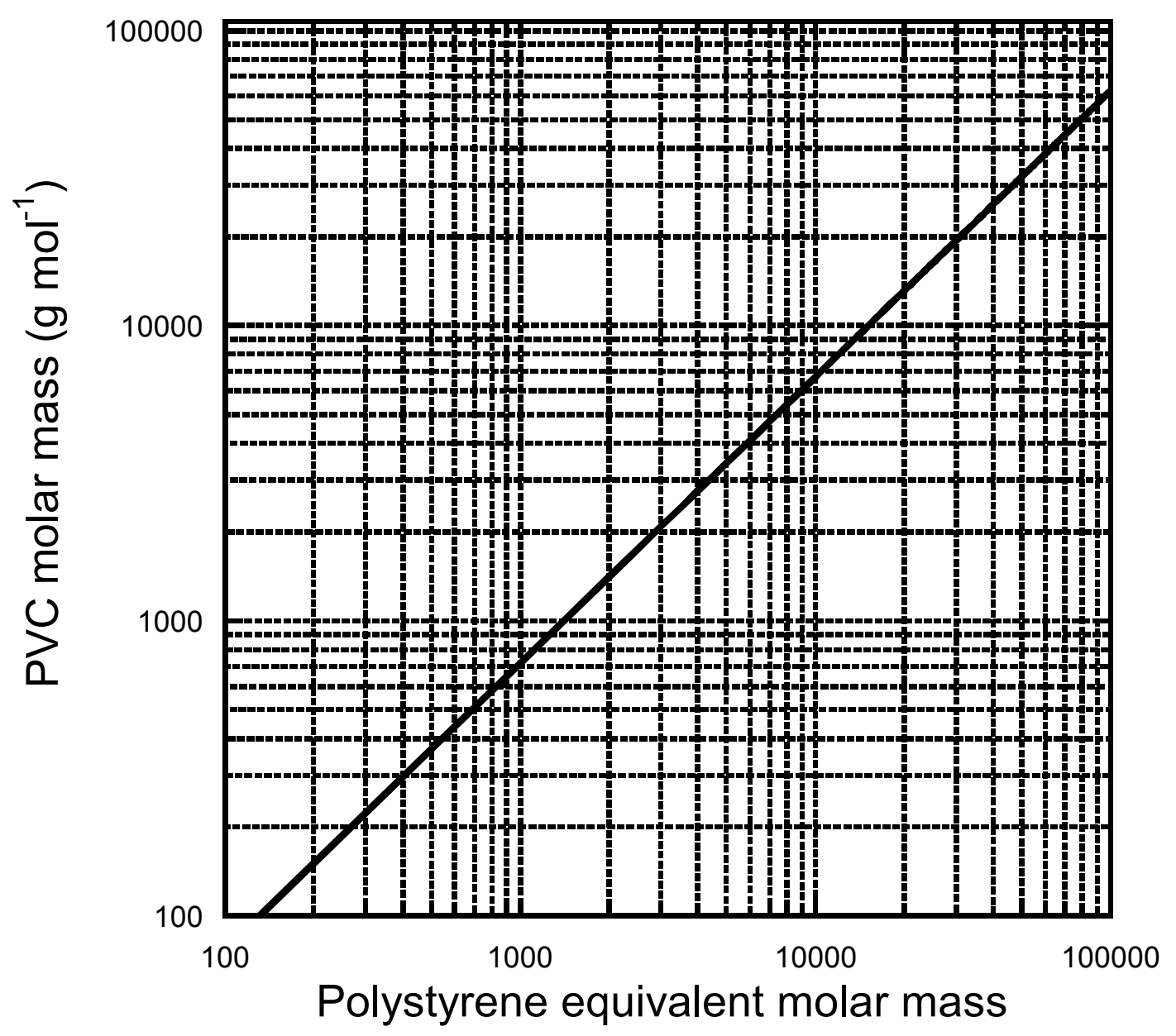

Figure S16. Correlation between absolute molar mass for PVC and GPC molar mass in polystyrene equivalents suggested by literature Mark-Houwink values. ${ }^{3}$ Figure reproduced from the Supporting Information of our previous paper. ${ }^{4}$ 


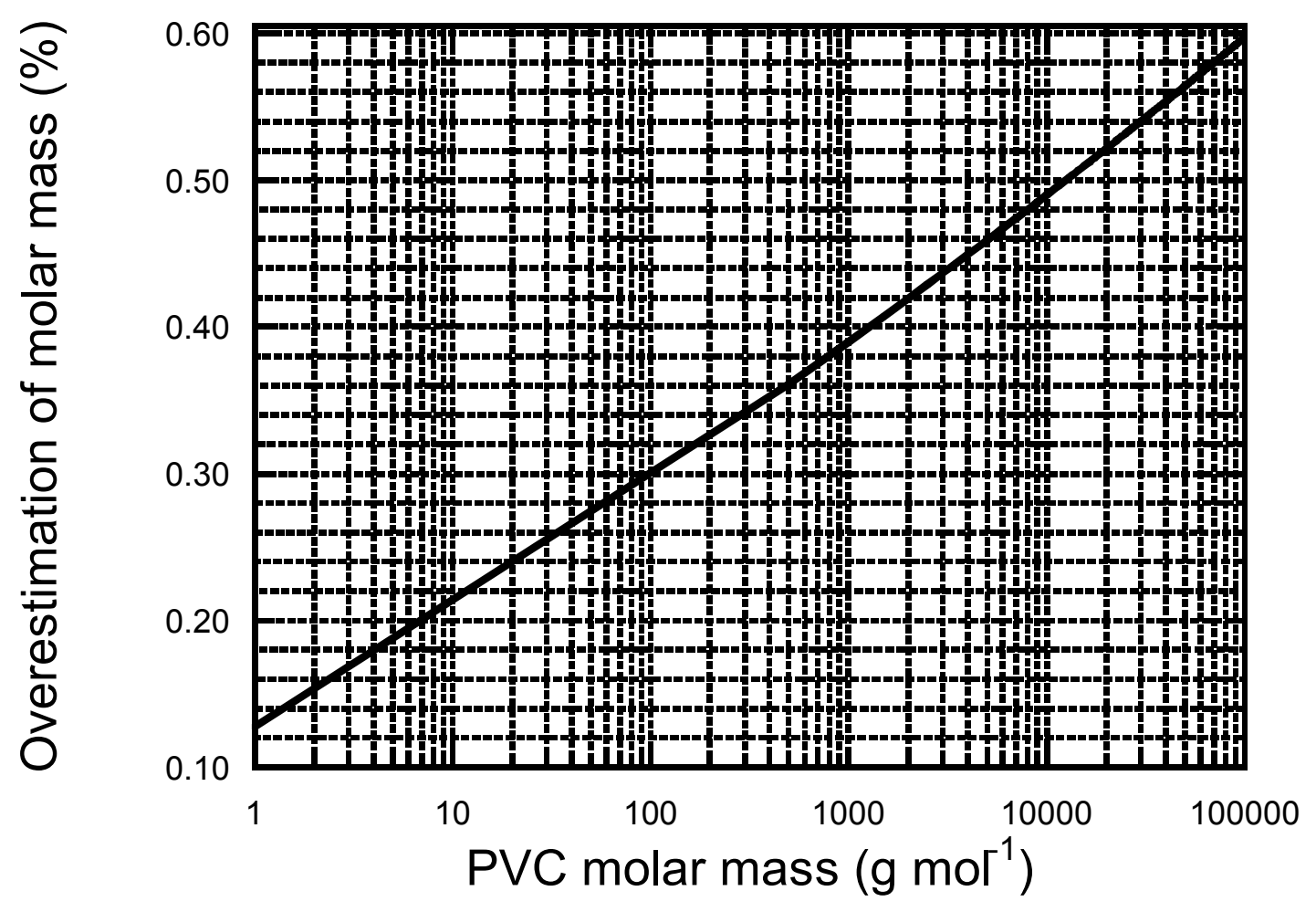

Figure S17. Overestimation of PVC molar mass caused by using polysturene equivalent molar mass values. Based on Mark Houwink values suggested by Skillicorn et al. ${ }^{3}$

PVC Mark Houwink values ${ }^{3}$ suggest that linear PVC homopolymer molar mass values in polystyrene equivalents may be high by $20-60 \%$ with respect to actual molar mass Figures S16, S17). These Mark Houwink values [for polystyrene in THF: $\mathrm{K}=12.58 \times$ $10^{-3}, \mathrm{a}=0.7155$, and for PVC in THF: $\left.\mathrm{K}=15.56 \times 10^{-3}, \alpha=0.7690\right]$ are based on analysis of essentially linear PVC with $16,000<M_{\mathrm{n}}<90,000{ }^{3}$ Similar Mark Houwink values for PVC were used Percec and coworkers ${ }^{5-7}$ to estimate molar mass values for PVC prepared by SET-RDRP based on GPC $M_{\mathrm{n}}$ values obtained as polystyrene equivalents.

The predicted discrepancy between PVC molar mass and polystyrene equivalent molar mass (Figure S17) is lower for lower molar masses. We note that in other recent work conducted by ouselves ${ }^{1,4}$ and others ${ }^{8}$ where low molar mass values $\left(M_{\mathrm{n}}<5000\right)$ were targeted, there is relatively good correspondence between found molar mass in PSequivalents and predicted PVC molar mass values.

Polymer architecture also has a significant influence on hydrodynamic volume such that the molar mass of star polymers may be significantly underestimated when using a calibration based on linear standards. ${ }^{9,10}$ 


\section{S10 References}

1. Sun, Z.; Choi, B.; Feng, A.; Moad, G.; Thang, S. H. Nonmigratory poly(vinyl chloride)-block-polycaprolactone plasticizers and compatibilizers prepared by sequential RAFT and ring-opening polymerization (RAFT-t-ROP). Macromolecules 2019, 52, 1746-1756. https://doi.org/10.1021/acs.macromol.8b02146

2. Li, W.; Chung, H.; Daeffler, C.; Johnson, J. A.; Grubbs, R. H. Application of (1)h dosy for facile measurement of polymer molecular weights. Macromolecules 2012, 45, 9595-9603. https://doi.org/10.1021/ma301666x

3. Skillicorn, D. E.; Perkins, G. G. A.; Slark, A.; Dawkins, J. V. Molecular weight and solution viscosity characterization of PVC. J. Vinyl Technol. 1993, 15, 105-108. https://doi.org/10.1002/vnl.730150211

4. Sun, Z.; Wang, M.; Li, Z.; Choi, B.; Mulder, R. J.; Feng, A.; Moad, G.; Thang, S. $\mathrm{H}$. Versatile approach for preparing PVC-based mikto-arm star additives based on RAFT polymerization. Macromolecules 2020, 53, 4465-4479. https://doi.org/10.1021/acs.macromol.0c00125

5. Percec, V.; Popov, A. V.; Ramirez-Castillo, E.; Monteiro, M.; Barboiu, B.; Weichold, O.; Asandei, A. D.; Mitchell, C. M. Aqueous room temperature metalcatalyzed living radical polymerization of vinyl chloride. J. Amer. Chem. Soc. 2002, 124, 4940-4941. https://doi.org/10.1021/ja0256055

6. Percec, V.; Popov, A. V.; Ramirez-Castillo, E.; Weichold, O. Living radical polymerization of vinyl chloride initiated with iodoform and catalyzed by nascent $\mathrm{cu} 0 /$ tris(2-aminoethyl)amine or polyethyleneimine in water at $25^{\circ} \mathrm{c}$ proceeds by a new competing pathways mechanism. J. Polym. Sci., Part A Polym. Chem. 2003, 41, 3283-3299. https://doi.org/https://doi.org/10.1002/pola.10937

7. Percec, V.; Guliashvili, T.; Ladislaw, J. S.; Wistrand, A.; Stjerndahl, A.; Sienkowska, M. J.; Monteiro, M. J.; Sahoo, S. Ultrafast synthesis of ultrahigh molar mass polymers by metal-catalyzed living radical polymerization of acrylates, methacrylates, and vinyl chloride mediated by set at $25^{\circ}$ c. J. Amer. Chem. Soc. 2006, 128, 14156-14165. https://doi.org/10.1021/ja065484z

8. Huang, Z.; Pan, P.; Bao, Y. Solution and aqueous miniemulsion polymerization of vinyl chloride mediated by a fluorinated xanthate. J. Polym. Sci., Part A Polym. Chem. 2016, 54, 2092-2101. https://doi.org/10.1002/pola.28074

9. Tobita, H.; Saito, S. Size exclusion chromatography of branched polymers: Star and comb polymers. Macromolecular Theory and Simulations 1999, 8, 513-519. https://doi.org/https://doi.org/10.1002/(SICI)1521-3919(19990901)8:5<513::AIDMATS513>3.0.CO;2-G

10. Ahn, S.; Lee, H.; Lee, S.; Chang, T. Characterization of branched polymers by comprehensive two-dimensional liquid chromatography with triple detection. Macromolecules 2012, 45, 3550-3556. https://doi.org/10.1021/ma2021985 